\section{Fertile addition}

\author{
Roger Gosden
}

Dynamics of Human Reproduction: Biology, Biometry, Demography. By James W. Wood. Aldine de Gruyter: 1995. Pp. 653. DM159, \$79.95 (hbk); DM80, \$39.95 (pbk).

CONSIDERING our teeming numbers, it seems odd that we are so infertile as a species, but that is nonetheless true comparatively speaking. A late puberty, lack of synchrony between coitus and ovulation, long inter-birth interval and a pregnancy wastage rate of around 50 per cent mean that successful pregnancies are few and far between. When and how often to reproduce are two of the most important decisions in life and, through evolutionary selection, we and our great-ape cousins have adopted an unhurried pace, for there is time and opportunity for repeated breeding attempts. Matters are rather different for ticks, termites and even turtles that live in more hazardous circumstances. They have to invest earlier and more heavily in breeding to ensure the survival of their lines. In Ogden Nash's words:

The turtle lives 'twixt plated decks

Which practically conceal its sex.

I think it clever of the turtle

In such a fix to be so fertile.

Behind these generalizations there is a rich tapestry of variation in human reproduction, and this forms the substance of James Wood's contribution. At heart is the concept of 'natural fertility', originally adumbrated by the French demographer Louis Henry in the 1950s and 1960s. The expression is easily misunderstood, and should not be equated with the biological potential to reproduce, or fecundity. Rather, it is fertility in the absence of deliberate control, and is modified by both physiological effects, such as breastfeeding, and cultural obligations, including sexual abstinence.

Gathering reliable population data for studying natural fertility is getting harder by the year because of the acculturation of traditional societies. Henry relied heavily on historical data from his own country to estimate natural fertility. Others have studied religious isolates such as the Amish and the Hutterite communities of North America or tribal societies such as the !Kung of Botswana and the Gainj of the highlands of Papua New Guinea (the author's speciality).

The plethora of variables potentially affecting fertility must be reduced to a manageable size to avoid becoming bogged down. Wood adopts the proximate determinants of fertility because they are computable variables, such as age at the menarche, marriage and menopause on the one hand, and the frequency of insemination, amenorrhoea and pregnancy loss (what he calls susceptibility factors) on the other. This is a fruitful strategy for mathematical modelling (often associated with John Bongaarts); and Wood uses proximate determinants as his rubric throughout the book because they mediate many fascinating influences on fertility. For instance, seasonal variation is still a mysterious influence, and peak fertility has been stable over historical time in some places, although no global pattern exists. What is more, the widespread assumption that the effects of seasonality or under-nutrition are simple adaptive traits for optimizing fertility do not bear close inspection. Age-specific fertility rates in females are more clear-cut because, irrespective of their levels, they decline steadily between the twenties and late forties in all populations.

Models of human reproduction have thrown light on many patterns and processes in reproduction - the fertile time of the menstrual cycle, influences of breast-feeding and nutrition, fetal loss, onset of permanent sterility and so on. But many gaps still need to be filled, especially in our knowledge of the male contribution and the role of genetic variation. Methodological difficulties abound and there are pitfalls for the unwary, which prompted the statistician Udny Yule to tease his colleagues nearly a century ago: the correlation that existed between the frequency of sightings of storks in English counties and the numbers of human births did not necessarily imply a direct causal influence.

A scholarly integration of the facts of reproductive biology and the figures of demography in some 650 pages packed with illustrations is an ambitious task for the most indefatigable of monograph writers, but Wood has done the job admirably well. His book will appeal mostly to graduate students and researchers in demography; and, apart from squirming at the occasional fact, I enjoyed it, as will anyone engaged in human reproductive biology. $\square$

Roger Gosden is at the Research School of Medicine, University of Leeds, Leeds LS2 9NS, UK.

\title{
The fascination of infestation
}

George C. McGavin

Insects Through the Seasons. By Gilbert Waldbauer. Harvard University Press: 1996. Pp. 289. \$24.95, £15.95.

GILBERT Waldbauer is one of those few lucky people paid to pursue their hobby. Reading Insects Through the Seasons, one discovers why he finds entomology endlessly fascinating. The large and beautiful saturniid moth Hyalophora cecropia that enthralled and intrigued the eight-yearold Waldbauer became one of his main research interests and is the star of the book. Details of its life cycle are used as stopping-off points to explore the many varied aspects of insect biology. Sex, violence and a cast of billions: what more could one possibly want? And as if his words, a blend of science and sentiment, were not enough to bring the subject to life, a cecropia moth flies across the bottom corner of the book as one flicks the pages.

Here readers will discover strange stories and fantastic facts about the lives of insects and the many ways in which millions of years of evolution have equipped these organisms, arguably the most successful on our planet, for survival. We also learn that evolution has provided other animals, and humans too, with some similar solutions to the problems of life in a hostile world.

In places I was left wanting a little more detail or explanation. There can be no doubting the benefits of complete metamorphosis as witnessed by most insect species that develop in this way, but why did it evolve? Is gradual metamorphosis really a compromise and did complete metamorphosis arise because it would be successful? Is there the taint of teleology here? But these are minor quibbles when viewed against the book as a whole.

When we try to bend the natural world to suit our own needs we can solve some problems, such as the control of the terrible screw-worm fly by the release of sterile males. But things can, of course, go wrong: for the sake of a little more honey we now have to cope with murderous killer bees.

Predation and parasitism, the author reminds us, are recurring themes in the insect world. And while most insects attack each other in an awesome variety of seemingly unpleasant ways, some turn their attention to humans. We are told of one medical entomologist who carefully recorded, in gruesome detail, the entire 50 days and 15.5 hours taken by two bot fly maggots to develop inside his own body. But the quest for knowledge does not normally demand such dedication. The book encourages us to take a close look at nature in general and insects in particular.

George C. McGavin is at the Oxford University Museum, Parks Road, Oxford OX1 3PW, UK. 